\title{
Synovial cysts of the cervicothoracic junction causing myelopathy: report of 3 cases and review of the literature
}

\author{
Erica F. Bisson, M.D., José-Carlos Sauri-Barraza, M.D., Toba Niazi, M.D., \\ AND MeIC H. SCHMidT, M.D., M.B.A. \\ Department of Neurosurgery, Clinical Neurosciences Center, University of Utah, Salt Lake City, Utah
}

\begin{abstract}
Synovial cysts are uncommon pathological entities in patients with cervical degenerative spinal disease, and there are only a few reports in the literature. Treatment typically involves decompression; however, biomechanical data indicate that laminectomies in the cervical spine also result in cervical instability, specifically within the cervicothoracic junction, supporting the use of fusion as well. The authors describe the use of fusion with decompression in the treatment of 3 patients with cervicothoracic synovial cysts that presented in an acute fashion with associated myelopathy and neurological decline, and they review the diagnostic elements, histopathology, and treatment of these cysts. All 3 of the patients did well with decompression via a posterior approach with a single-level instrumented fusion from C-7 to T-1. Each patient regained complete neurological function and had no residual neurological deficits. These results are promising, although the sample size of 3 cases is too small to make any conclusive evaluations. Future studies incorporating Class I and Class II data are imperative to make firm conclusions regarding general management of this rare entity.
\end{abstract}

(http://thejns.org/doi/abs/10.3171/2013.3.FOCUS1385)

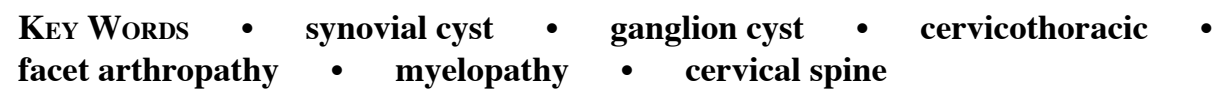

$\mathrm{S}$ YNOVIAL cysts are an uncommon pathological condition in the cervical spine. The great majority of synovial cysts are found in the lumbar spine,,$^{23,32}$ making presentation in other spinal regions very rare. Most reports of lower cervical spinal cysts in the literature describe single cases that have not resulted in significant neurological deficits. $5,7,9,11-13,17,21,23,31,34,36,37,41,43,45,50-52,56,58,60$ The treatment of choice is posterior surgical decompression. Fusion augmentation is still controversial, but recent studies have supported its use in the lumbar spine, in particular, to avoid recurrence and back pain. ${ }^{4,59} \mathrm{Here}$, we present 3 cases of cervicothoracic synovial cysts causing myelopathy and discuss the diagnostic elements, histopathological findings, and treatment.

\section{Case Reports}

Case 1

History and Examination. A 65-year-old man presented to the clinic with a 3-week history of numbness in the left leg. The numbness had progressed and involved gait disturbances. At presentation, he had numbness extending from the abdomen to both legs related to myelop- athy. A CT scan provided poor visualization of the lower cervical spine because of the patient's body habitus, indicating only moderate facet arthropathy at C6-7 and C7T1, with no evidence of spinal canal or neural foraminal compromise. Magnetic resonance imaging showed an extradural cystic lesion adjacent to the left C7-T1 facet joint, with centrally high $\mathrm{T} 2$ signal and intermediate-tolow T1 signal, and severe compression of the spinal cord. There was peripheral enhancement after administration of gadolinium contrast medium, but the central cystic component demonstrated no enhancement (Fig. 1).

Surgical Intervention and Postoperative Course. The patient underwent C7-T1 laminectomy with microsurgical resection of the cyst using neuromonitoring and C7-T1 instrumented fusion with local bone graft. During resection, the cyst was noted to be adhering to the dura mater. The pathology report indicated that the lesion was consistent with a synovial cyst. In the 3-year follow-up period, the patient has recovered complete neurological function.

Case 2

History and Examination. A 43-year-old man presented with a 1-month history of increasing numbness extend- 

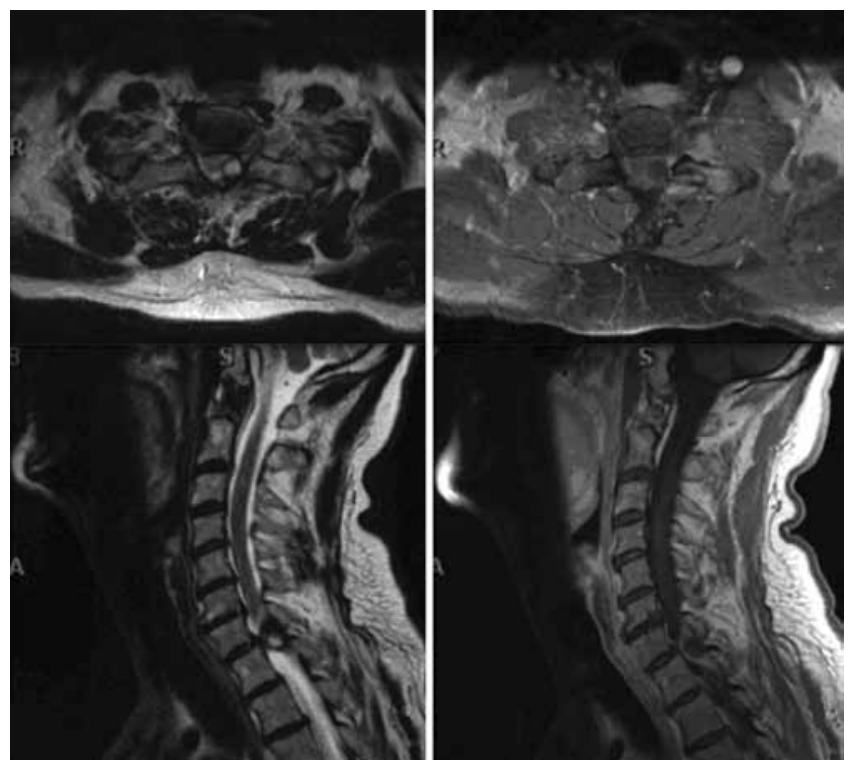

FIG. 1. Case 1. Left: T2-weighted MR images showing a cystic formation at C7-T1. Right: T1-weighted MR images obtained after administration of a contrast agent showing enhancement of the cystic capsule.

ing to the upper chest and gait disturbances. On physical examination, he presented with a motor deficit of $4 / 5$ in his lower extremities, a normal sensory level at T-3 but altered sensitivity below that level, hyperreflexia, and bilateral Babinski sign. A CT scan demonstrated a $15 \times 11-\mathrm{mm}$ extradural cystic-appearing lesion at C-7 in the left posterior aspect of the spinal canal that slightly deformed the cord. Sclerosis and scalloping of the adjacent bone with thinning of the left lamina of T-1 and multilevel facet hypertrophy from C-4 to T-1 were observed. The MRI study, however, showed an extradural cystic lesion in the right posterolateral aspect of C7-T1, with centrally high T2 signal and intermediate-to-low $\mathrm{T} 1$ signal, and severe compression of the spinal cord (Fig. 2).

Surgical Treatment and Postoperative Course. The patient was treated surgically with a C7-T1 laminectomy with microsurgical resection of the cyst using neuromonitoring and a C7-T1 instrumented fusion with local bone graft. Histopathologically, the tissue was soft and reddish pink. Microscopically, fragments of fibroadipose and fibrocartilaginous tissues with an inflammatory reaction were observed. No neoplasm was identified. At his 12-month follow-up examination, the patient was completely recovered and had no neck pain.

\section{Case 3}

History and Examination. A 58-year-old man presented to the emergency room with numbness from the nipples down. He had been referred from another hospital, where he had been treated with steroids. The patient had had a ground-level fall 6 weeks earlier and had acute onset of numbness in his lower extremities 1 month before presentation. The numbness progressed to a complete loss of sensation and proprioception in his lower extremities up to a T-4 sensory level. On examination, neither motor
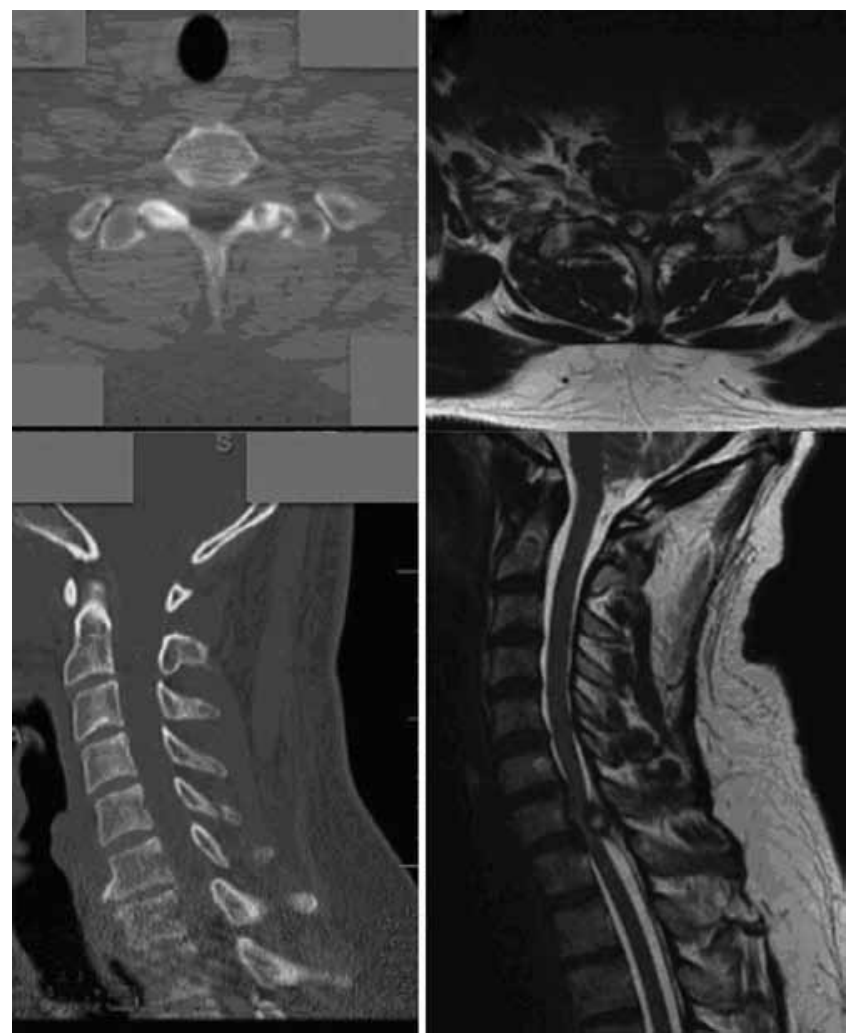

Fig. 2. Case 2. Left: CT scans showing a posterior extradural mass at C7-T1. Right: T2-weighted MR images without contrast enhancement clearly showing a posterior cystic formation at C7-T1.

deficit nor bladder or bowel dysfunction was found, and his deep tendon reflexes were normal.

Severe generalized cervical degenerative changes were noted on the CT scan, with a $1-\mathrm{cm}$ focus of air lucency projecting into the right posterolateral aspect of the spinal canal at the C7-T1 level, likely representing air within a synovial cyst projecting anteromedially from the right C7-T1 facet joint. The cyst appeared to have a calcified shell, resulting in at least moderate spinal canal stenosis and severe narrowing of the subarticular region. An anterolisthesis in C7-T1 of $2.9 \mathrm{~mm}$ was observed. Magnetic resonance imaging showed a severe narrowing of the right subarticular region secondary to a right posterolateral $0.9 \times 1.6 \times 1.9-\mathrm{cm}$ extradural mass. This mass was characterized by heterogeneous, predominantly low T2 signal, with low T1 signal centrally and T1 signal isointense to the cord peripherally (associated with air signal centrally), and minimal rim enhancement. It had a discrete T2-hypointense rim. A moderate facet arthropathy, greater on the right side, was noted, and an area of high T2 and short-tau inversion recovery (STIR) signal within the cord adjacent to the cyst was identified (Fig. 3).

Surgical Intervention and Postoperative Course. The patient underwent a C7-T1 laminectomy with microsurgical resection of the cyst using neuromonitoring and a C7-T1 instrumented fusion with local bone graft (Fig. $3)$. Adhesions from the cyst to the dura where found. No complications occurred during the procedure. The pathology report described a red-tan, irregular, bony, soft-tissue 


\section{Synovial cysts of the cervicothoracic junction causing myelopathy}

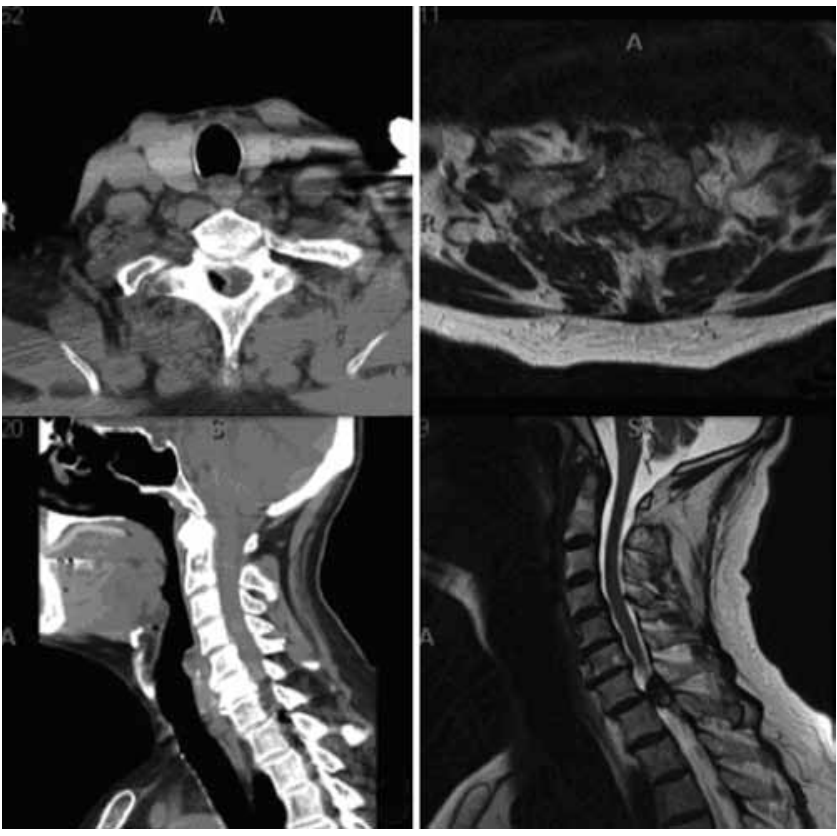

Fig. 3. Case 3. Left: CT scans demonstrating a cystic formation containing gas. Right: T2-weighted MR images showing the right cystic formation.

fragment measuring $2.0 \times 1.5 \times 1.1 \mathrm{~cm}$. Microscopically, there were fragments of benign, synovial membrane-lined fibrocartilaginous tissue and bone. The patient had complete neurological recovery immediately postoperatively and minimal neck pain at the 1-month follow-up visit.

\section{Literature Review}

A Medline and PubMed search was performed using key words "synovial cyst," "ganglion cyst," "spinal cyst," and "juxtafacet cyst," related to the cervicothoracic junction. The identified articles were reviewed in detail, and other appropriate references were obtained.

\section{Results}

We identified 15 papers describing 27 patients with epidural cystic formations in the cervical and thoracic area. Combining these cases with the 3 new cases reported in the present paper yielded 30 cases for analysis.

\section{Epidemiology}

Frequency. Among 183 patients who underwent decompressive cervical or thoracic spine surgery performed by the senior author, we found that $1.6 \%$ had cysts in the cervicothoracic region.

Age and Sex. Of the 30 identified cases, 22 (76\%) involved men, 7 (24\%) involved women, and in one case, the patient's sex was not specified, yielding a 3.1:1 maleto-female ratio. The average age was $64.2 \pm 10.8$ years (range $41-80$ years), with most patients presenting in their 7 th decade (Fig. 4).

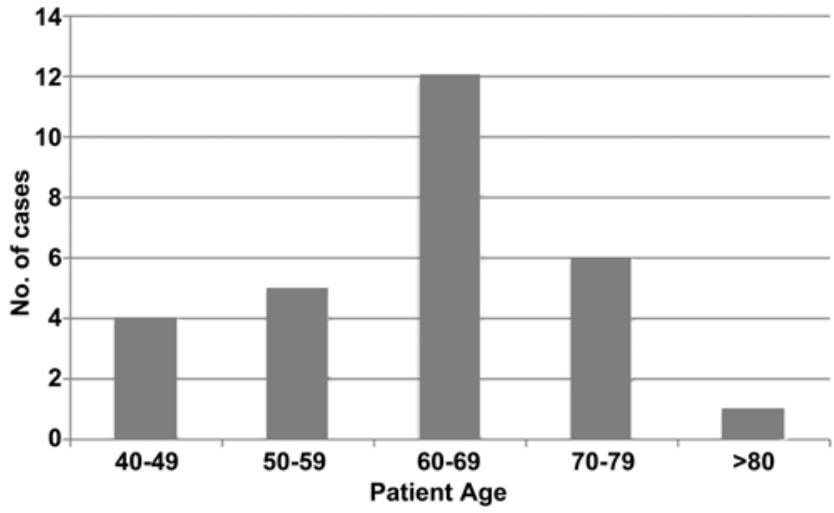

FIG. 4. Graph showing the age distribution (in years) of patients presenting with cervicothoracic synovial cyst.

\section{Clinical Presentation}

Myelopathy alone was the most common clinical syndrome, occurring in 15 cases (50\%), followed by radiculopathy alone in 14 cases (47\%), and mixed symptomatology in 1 case $(1 \%)$.

\section{Treatment}

Posterior decompression and resection was the most common surgical procedure; it was performed in 25 cases $(83 \%)$. Fusion augmentation was performed in only 4 cases (13\%) including the 3 in our series. In 1 case (3\%), only conservative treatment was provided because the patient wanted to delay surgery; at the 6-month follow-up, the patient's symptoms had mostly resolved and there was no evidence of the cyst on MR images. ${ }^{11}$

\section{Outcome}

In 26 cases $(86 \%)$ data were available for outcome evaluation. Follow-up data were available for $12(80 \%)$ of the 15 patients who presented with myelopathy; similarly, $13(92 \%)$ of 14 patients who presented with radiculopathy were monitored after surgery. Although the general clinical outcome was favorable in all reports, the best outcome was for patients treated for radiculopathy (Fig. 5).

Only $14(47 \%)$ of the 30 patients were monitored postoperatively, with a mean follow-up of $17.5 \pm 16.1$ months

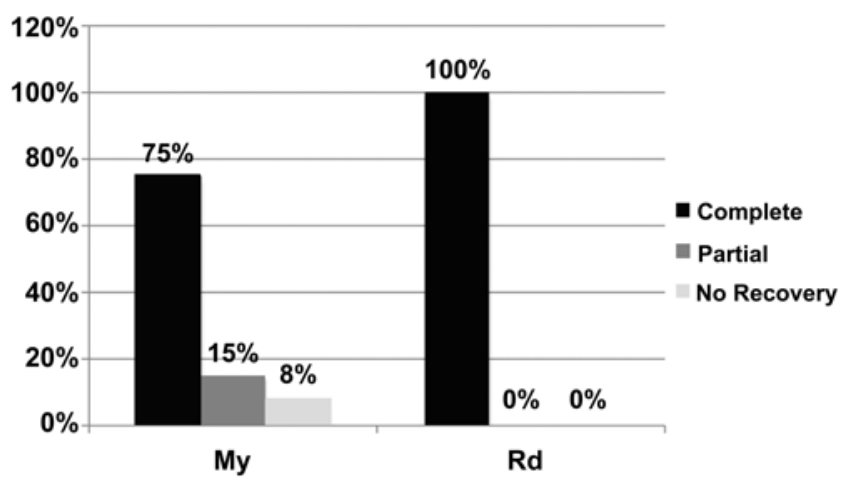

FIG. 5. Graph showing the clinical outcome of myelopathy (My) and radiculopathy $(\mathrm{Rd})$ for patients with synovial cysts in the cervicothoracic junction. 
(range 2-60 months). There were no reports of cyst recurrence or postoperative need for fusion after laminectomy.

\section{Discussion}

The frequency of synovial cysts in the cervicothoracic junction is unknown. This may be due to the rarity of the entity; we found only 15 papers reporting on synovial cysts in this region (Table 1). $5,7,9,11-13,17,23,36,37,43,50-52,58$ However, we report a synovial cyst prevalence of $1.6 \%$ among patients who underwent subaxial cervical or upper thoracic surgery performed by the senior author. The first report of a synovial cyst in the cervical spine was in 1974 by Kao et al. ${ }^{33}$ The cause of synovial cysts is not yet clearly identified, but they have been related to degenerative spinal facet disease, ${ }^{42}$ rheumatoid arthritis, ${ }^{15}$ postoperative segmental spinal instability, ${ }^{30}$ trauma, spondylolisthesis, and abnormal joint movement. ${ }^{10,13,41}$ In our cases, only one cyst related to trauma, and plain radiographs and CT demonstrated degenerative changes in all 3 patients. These degenerative changes can also be age-related, but the mean age of our patients (55.3 years) is younger than that of the typical patient with synovial cysts described in the literature, who is described as being in his or her mid60 s. $^{10,16}$ Several theories have been suggested to explain the pathophysiology of these cysts, in particular for ganglion cysts, ${ }^{52}$ including the chronic joint capsule weakness theory, ${ }^{21,46,52}$ the myxoid degeneration theory, ${ }^{10,21}$ the trauma theory, $, 3,31,39$ the inflammatory process theory, ${ }^{2}$ and the stress theory. 15,55

Histologically, cysts related to the facet joints can be classified as "synovial cysts" or as "ganglion cysts," which are also known as "pseudocysts." Synovial cysts (true cysts) rigorously present a capsule with a synovial lining, typically contain a clear and serous fluid, and have a direct connection to the facet joint. ${ }^{33}$ In contrast, ganglion

TABLE 1: Summary of symptoms, treatment, and outcome in reported cases of synovial cysts of the cervicothoracic junction*

\begin{tabular}{|c|c|c|c|c|c|}
\hline Authors \& Year & Age (yrs), Sex & Symptoms & Treatment & $\mathrm{FU}$ (mos) & Recovery \\
\hline Cartwright et al., 1985 & $41, M$ & My & PLR & 12 & complete \\
\hline Epstein \& Hollingsworth, 1993 & $47, M$ & $\mathrm{Rd}$ & PLR & NS & NS \\
\hline Freidberg et al., 1994 & NS & My & PLR & 60 & complete \\
\hline Kotilainen \& Marttila, 1997 & $64, M$ & My & PLR & 2 & complete \\
\hline \multirow[t]{9}{*}{ Krauss et al., 1998} & $66, \mathrm{M}$ & $\mathrm{Rd}$ & PLR & NS & complete \\
\hline & $69, \mathrm{M}$ & $\mathrm{Rd}$ & PLR & NS & complete \\
\hline & $79, \mathrm{~F}$ & $\mathrm{Rd}$ & PLR & NS & complete \\
\hline & $68, M$ & $\mathrm{Rd}$ & PLR & NS & complete \\
\hline & $58, F$ & $\mathrm{Rd}$ & PLR & NS & complete \\
\hline & $59, \mathrm{M}$ & My & PLR & NS & none \\
\hline & $76, \mathrm{M}$ & $\mathrm{Rd}$ & PLR & NS & complete \\
\hline & $65, M$ & $\mathrm{Rd}$ & PLR & NS & complete \\
\hline & $64, F$ & $\mathrm{Rd}$ & PLR + fusion & NS & complete \\
\hline \multirow[t]{2}{*}{ Cudlip et al., 1999} & $61, M$ & My & PLR & 6 & partial \\
\hline & $61, \mathrm{M}$ & My & PLR & 12 & complete \\
\hline Stoodley et al., 2000 & $65, M$ & $\mathrm{Rd}$ & PLR & 5 & complete \\
\hline \multirow[t]{3}{*}{ Shima et al., 2002} & $66, M$ & My & PLR & 9 & partial \\
\hline & $68, M$ & $\mathrm{Rd}$ & PLR & NS & complete \\
\hline & $72, \mathrm{~F}$ & My & PLR & NS & complete \\
\hline Cho et al., 2004 & $80, M$ & My & PLR & NS & complete \\
\hline Miwa et al., 2004 & $74, \mathrm{~F}$ & $\mathrm{Rd}$ & PLR & 36 & complete \\
\hline Song et al., 2006 & $74, \mathrm{M}$ & My & PLR & NS & NS \\
\hline Colen \& Rengachary, 2006 & $58, F$ & $\mathrm{Rd}$ & conservative & 6 & complete \\
\hline \multirow[t]{2}{*}{ Christophis et al., 2007} & $74, \mathrm{~F}$ & My & PLR & 12 & NS \\
\hline & $58, \mathrm{M}$ & My & PLR & 12 & NS \\
\hline Vastagh et al., 2008 & $44, \mathrm{M}$ & $M y+R d$ & PLR & 18 & complete \\
\hline Costa et al., 2010 & $84, \mathrm{M}$ & $\mathrm{Rd}$ & PLR & NS & complete \\
\hline \multirow[t]{3}{*}{ present report } & $65, M$ & My & PLR + fusion & 36 & complete \\
\hline & $43, M$ & My & PLR + fusion & 12 & complete \\
\hline & $58, M$ & My & PLR + fusion & NS & complete \\
\hline
\end{tabular}

* FU = follow-up; My = myelopathy; NS = not specified; PLR = posterior laminotomy and resection; Rd = radiculopathy. 


\section{Synovial cysts of the cervicothoracic junction causing myelopathy}

cysts lack a synovial lining and have a fibrous connective tissue wall instead; the content is characterized by myxoid gelatinous, highly viscous fluid, and even if the cyst is related to the facet joint, there is no direct connection. ${ }^{50}$ Ganglion cysts may be also found in the ligamentum flavum. ${ }^{53,56,60}$ The term "juxtafacet cysts" has been proposed to encompass both synovial and ganglion cysts. ${ }^{33}$ Moreover, there is a possibility that ganglions may be a chronic form of synovial cysts. ${ }^{18,21,26,29,52}$ In a 9-case series of cysts in the thoracic spine, synovial cysts made up $34.5 \%$ of cases. ${ }^{10}$ We present 3 cases of true synovial cysts.

The clinical presentation of patients with synovial cysts can include radiculopathy, myelopathy, neck pain, or a mixture of these syndromes. In the 3 cases that we report, the patients all presented with pure myelopathy. Although the natural history is unpredictable, the 3 patients presented with a progressive myelopathy pattern from 3 to 6 weeks after the onset of symptoms. Radiographs can be used to find nonspecific degenerative changes in the facet joints or adjacent structures and even bone erosion. Dynamic radiographs are useful as a support for the diagnosis of instability associated with a synovial cyst. In patients with instability, an instrumented fusion should be considered as part of the surgical treatment. Neurodiagnostic studies are very helpful to differentiate these cysts from other extradural or intradural compressive syndromes. Myelography is sensitive for demonstrating an extradural lesion, but it is nonspecific. ${ }^{23}$ When the cyst is calcified or contains gas, CT scans show a posterolateral round epidural lesion. . $^{23,24,38,45}$ Otherwise, CT scans are nonspecific. Magnetic resonance imaging is the diagnostic study of choice because of the soft-tissue origin of the cysts. The MRI characteristics of these lesions depend on the content of the cysts. ${ }^{8,10,24}$ Signal intensity may be isointense to cerebrospinal fluid in cases in which the cyst contains relatively clear synovial fluid,,$^{24,34}$ but it may change depending on the protein content, ${ }^{24}$ and the presence and age of hemorrhagic products and air, ${ }^{19}$ and calcification of the rim. ${ }^{34}$ Enhancement of the cystic wall with gadopentetate dimeglumine reflects the relatively increased vascularity of the capsule. ${ }^{24}$

Because synovial cysts may be associated with hemorrhage, inflammation, and bone erosion, misdiagnosis as another pathological condition associated with inflammation or hemorrhage, such as tumor, infection, or other arthropathies, is possible. The differential diagnosis of these cysts must include epidural and some intradural compressive syndromes of the spine.

Misinterpretation of a synovial cyst as an extruded disc herniation on the basis of CT findings has been reported. ${ }^{46}$ Neoplasms such as extradural metastases, extradural meningioma, schwannoma (neurinoma), hematopoietic disease (such as lymphoma), chordoma, epidermoid and dermoid cysts,,${ }^{25}$ cystic teratomas, ${ }^{54}$ and cystic neurofibroma can also be confused for synovial cysts. ${ }^{20,22}$

Spinal meningeal cysts ${ }^{40,44}$ including both extradural arachnoid cysts ${ }^{28}$ and Tarlov perineural cysts, should also be considered in the differential diagnosis. ${ }^{28,34}$ Several other cysts of the spine can be confused with cervical and thoracic epidural cystic formations. Hydatid cysts $25,28,40$ are parasitic cysts caused by Echinococcus granulosus, which is endemic to the Middle East, South America, New Zealand, and Mediterranean countries. Ependymal ${ }^{27,40,47}$ and enterogenous ${ }^{40,49,57}$ cysts also may be confused with synovial cysts.

Surgical intervention is the gold standard for treating a synovial cyst in the cervical spine. We found only a single reported case of a synovial cyst in the cervical spine that was successfully treated conservatively. In that case, the cyst resolved during the 6-month period following diagnosis. ${ }^{11}$ Posterior decompression surgery is the treatment of choice for cervical synovial cysts. The role of fusion is still controversial. It has been shown that patients with synovial cysts in the lumbar spine who undergo laminectomy and fusion have lower incidences of cyst recurrence and back pain than those who undergo laminectomy alone., ${ }^{4,59}$ When patients with lumbar synovial cysts are treated with decompression alone, there is a greater possibility of the development or progression of listhesis than when they are treated with decompression and fusion. ${ }^{16}$ Presentation in the cervicothoracic junction, such as in the cases we describe, has special biomechanical characteristics, because the rigid thoracic spine meets the flexible cervical spine at this junction, and there is a higher risk of instability than in other areas of the cervical or thoracic spine. ${ }^{3,6,48}$ Laminectomies performed to treat other pathological conditions have been demonstrated to cause instability in this region, and so fusion is suggested. ${ }^{1,14,35}$ Therefore, to avoid instability, cyst recurrence, and postoperative neck pain, we suggest augmenting resection of the cyst with a short-segment pedicle-instrumented C7-T1 fusion.

\section{Disclosure}

The authors report no conflict of interest concerning the materials or methods used in this study or the findings specified in this paper.

Author contributions to the study and manuscript preparation include the following. Conception and design: Schmidt. Acquisition of data: Sauri-Barraza, Niazi. Analysis and interpretation of data: Bisson, Sauri-Barraza, Niazi. Drafting the article: Bisson, Sauri-Barraza, Niazi. Critically revising the article: Schmidt, Bisson. Reviewed submitted version of manuscript: Schmidt, Bisson, SauriBarraza. Approved the final version of the manuscript on behalf of all authors: Schmidt.

\section{Acknowledgment}

The authors thank Kristin Kraus, M.Sc., for assistance in preparing this paper.

\section{References}

1. Albert TJ, Klein GR, Joffe D, Vaccaro AR: Use of cervicothoracic junction pedicle screws for reconstruction of complex cervical spine pathology. Spine (Phila Pa 1976) 23:15961599, 1998

2. Almefty R, Arnautović KI, Webber BL: Multilevel bilateral calcified thoracic spinal synovial cysts. Report of 4 cases. J Neurosurg Spine 8:473-477, 2008

3. An HS, Vaccaro A, Cotler JM, Lin S: Spinal disorders at the cervicothoracic junction. Spine (Phila Pa 1976) 19:25572564, 1994

4. Bydon A, Xu R, Parker SL, McGirt MJ, Bydon M, Gokaslan ZL, et al: Recurrent back and leg pain and cyst reformation after surgical resection of spinal synovial cysts: systematic 
review of reported postoperative outcomes. Spine J 10:820826,2010

5. Cartwright MJ, Nehls DG, Carrion CA, Spetzler RF: Synovial cyst of a cervical facet joint: case report. Neurosurgery 16:850-852, 1985

6. Chapman JR, Anderson PA, Pepin C, Toomey S, Newell DW, Grady MS: Posterior instrumentation of the unstable cervicothoracic spine. J Neurosurg 84:552-558, 1996

7. Cho BY, Zhang HY, Kim HS: Synovial cyst in the cervical region causing severe myelopathy. Yonsei Med J 45:539-542, 2004

8. Choe W, Walot I, Schlesinger C, Chambi I, Lin F: Synovial cyst of dens causing spinal cord compression. Case report. Paraplegia 31:803-807, 1993

9. Christophis P, Asamoto S, Kuchelmeister K, Schachenmayr W: "Juxtafacet cysts", a misleading name for cystic formations of mobile spine (CYFMOS). Eur Spine J 16:1499-1505, 2007

10. Cohen-Gadol AA, White JB, Lynch JJ, Miller GM, Krauss WE: Synovial cysts of the thoracic spine. J Neurosurg Spine 1:52-57, 2004

11. Colen CB, Rengachary S: Spontaneous resolution of a cervical synovial cyst. Case illustration. J Neurosurg Spine 4:186, 2006

12. Costa F, Menghetti C, Cardia A, Fornari M, Ortolina A: Cervical synovial cyst: case report and review of literature. Eur Spine J 19 (2 Suppl 2):S100-S102, 2010

13. Cudlip S, Johnston F, Marsh H: Subaxial cervical synovial cyst presenting with myelopathy. Report of three cases. J Neurosurg 90 (1 Suppl):141-144, 1999

14. Ebara S, Yuzawa Y, Kinoshita T, Takahashi J, Nakamura I, Hirabayashi $\mathrm{H}$, et al: A neurofibromatosis type 1 patient with severe kyphoscoliosis and intrathoracic meningocele. J Clin Neurosci 10:268-272, 2003

15. Eguchi K, Migita K, Nakashima M, Ida H, Terada K, Sakai M, et al: Fibroblast growth factors released by wounded endothelial cells stimulate proliferation of synovial cells. J Rheumatol 19:1925-1932, 1992

16. Epstein NE: Lumbar synovial cysts: a review of diagnosis, surgical management, and outcome assessment. J Spinal Disord Tech 17:321-325, 2004

17. Epstein NE, Hollingsworth R: Synovial cyst of the cervical spine. J Spinal Disord 6:182-185, 1993

18. Eyster EF, Scott WR: Lumbar synovial cysts: report of eleven cases. Neurosurgery 24:112-115, 1989

19. Favre G, Javier-Moder RM, Hauber M, Zoellner G, Munoz A, Maîtrot D, et al: [Radicular syndrome and synovial cyst of the zygapophyseal joints: two case-reports.] Rev Med Interne 25:230-233, 2004 (Fr)

20. Finkelstein SD, Sayegh R, Watson P, Knuckey N: Juxta-facet cysts. Report of two cases and review of clinicopathologic features. Spine (Phila Pa 1976) 18:779-782, 1993

21. Fonoff ET, Dias MP, Tarico MA: Myelopathic presentation of cervical juxtafacet cyst: a case report. Spine (Phila Pa 1976) 29:E538-E541, 2004

22. Frank BL, Harrop JS, Hanna A, Ratliff J: Cervical extradural meningioma: case report and literature review. J Spinal Cord Med 31:302-305, 2008

23. Freidberg SR, Fellows T, Thomas CB, Mancall AC: Experience with symptomatic spinal epidural cysts. Neurosurgery 34:989-993, 1994

24. Fritz RC, Kaiser JA, White AH, DeLong WB, Gamburd RS: Magnetic resonance imaging of a thoracic intraspinal synovial cyst. Spine (Phila Pa 1976) 19:487-490, 1994

25. Graham E, Lenke LG, Hannallah D, Lauryssen C: Myelopathy induced by a thoracic intraspinal synovial cyst: case report and review of the literature. Spine (Phila Pa 1976) 26:E392E394, 2001

26. Heary RF, Stellar S, Fobben ES: Preoperative diagnosis of an extradural cyst arising from a spinal facet joint: case report. Neurosurgery 30:415-418, 1992
27. Hodges SD, Fronczak S, Zindrick MR, Lorenz MA, Vrbos LA: Extradural synovial thoracic cyst. Spine (Phila Pa 1976) 19:2471-2473, 1994

28. Houten JK, Sanderson SP, Cooper PR: Spontaneous regression of symptomatic lumbar synovial cysts. Report of three cases. J Neurosurg 99 (2 Suppl):235-238, 2003

29. Hsu KY, Zucherman JF, Shea WJ, Jeffrey RA: Lumbar intraspinal synovial and ganglion cysts (facet cysts). Ten-year experience in evaluation and treatment. Spine (Phila Pa 1976) 20:80-89, 1995

30. Ikuta K, Tono O, Oga M: Prevalence and clinical features of intraspinal facet cysts after decompression surgery for lumbar spinal stenosis. Clinical article. J Neurosurg Spine 10:617622,2009

31. Jabre A, Shahbabian S, Keller JT: Synovial cyst of the cervical spine. Neurosurgery 20:316-318, 1987

32. Kahiloğullari G, Tuna H, Attar A: Management of spinal synovial cysts. Turk Neurosurg 18:211-214, 2008

33. Kao CC, Winkler SS, Turner JH: Synovial cyst of spinal facet. Case report. J Neurosurg 41:372-376, 1974

34. Kayser F, Divano L, Vermer JF: [Ganglion cyst of the cervical spine causing radiculopathy.] J Radiol 79:687-689, 1998 (Fr)

35. Korovessis P, Katonis P, Aligizakis A, Christoforakis J, Baikousis A, Papazisis Z, et al: Posterior compact Cotrel-Dubousset instrumentation for occipitocervical, cervical and cervicothoracic fusion. Eur Spine J 10:385-394, 2001

36. Kotilainen E, Marttila RJ: Paraparesis caused by a bilateral cervical synovial cyst. Acta Neurol Scand 96:59-61, 1997

37. Krauss WE, Atkinson JL, Miller GM: Juxtafacet cysts of the cervical spine. Neurosurgery 43:1363-1368, 1998

38. Lin RM, Wey KL, Tzeng CC: Gas-containing "ganglion” cyst of lumbar posterior longitudinal ligament at L3. Case report. Spine (Phila Pa 1976) 18:2528-2532, 1993

39. Lynn B, Watkins RG, Watkins RG IV, Williams LA: Acute traumatic myelopathy secondary to a thoracic cyst in a professional football player. Spine (Phila Pa 1976) 25:1593-1595, 2000

40. Marbacher S, Barth A, Arnold M, Seiler RW: Multiple spinal extradural meningeal cysts presenting as acute paraplegia. Case report and review of the literature. J Neurosurg Spine 6:465-472, 2007

41. McGuigan C, Stevens J, Gabriel CM: A synovial cyst in the cervical spine causing acute spinal cord compression. Neurology 65:1293, 2005

42. Merkle M, Psaras T, Tatagiba M, Danz S, Schmidt F: Synovial cyst of the thoracic spine causing myelopathy. Spine (Phila Pa 1976) 34:E199-E201, 2009

43. Miwa M, Doita M, Takayama H, Muratsu H, Harada T, Kurosaka M: An expanding cervical synovial cyst causing acute cervical radiculopathy. J Spinal Disord Tech 17:331-333, 2004

44. Nabors MW, Pait TG, Byrd EB, Karim NO, Davis DO, Kobrine AI, et al: Updated assessment and current classification of spinal meningeal cysts. J Neurosurg 68:366-377, 1988

45. Nijensohn E, Russell EJ, Milan M, Brown T: Calcified synovial cyst of the cervical spine: CT and MR evaluation. J Comput Assist Tomogr 14:473-476, 1990

46. Onofrio BM, Mih AD: Synovial cysts of the spine. Neurosurgery 22:642-647, 1988

47. Ranjan R, Tewari R, Kumar S: Cervical intradural extramedullary ependymal cyst associated with congenital dermal sinus: a case report. Childs Nerv Syst 25:1121-1124, 2009

48. Sauri-Barraza JC, Vital JM, Pointillart V, Aurouer N, Gille O, Gangnet N: Vois d'abord de la charnière cervicothoracique. Rachis 2:4-6, 2007

49. Shetty DS, Lakhkar BN: Cervico-dorsal spinal enterogenous cyst. Indian J Pediatr 67:304-306, 2000

50. Shima Y, Rothman SL, Yasura K, Takahashi S: Degenerative intraspinal cyst of the cervical spine: case report and literature review. Spine (Phila Pa 1976) 27:E18-E22, 2002 


\section{Synovial cysts of the cervicothoracic junction causing myelopathy}

51. Song JK, Musleh W, Christie SD, Fessler RG: Cervical juxtafacet cysts: case report and literature review. Spine J 6:279281,2006

52. Stoodley MA, Jones NR, Scott G: Cervical and thoracic juxtafacet cysts causing neurologic deficits. Spine (Phila Pa 1976) 25:970-973, 2000

53. Sudo H, Abumi K, Ito M, Kotani Y, Takahata M, Hojo Y, et al: Spinal cord compression by ligamentum flavum hematoma in the thoracic spine. Spine (Phila Pa 1976) 34:E942-E944, 2009

54. Sung KS, Sung SK, Choi HJ, Song YJ: Spinal intradural extramedullary mature cystic teratoma in an adult. J Korean Neurosurg Soc 44:334-337, 2008

55. Szekanecz Z, Koch AE: Update on synovitis. Curr Rheumatol Rep 3:53-63, 2001

56. Takano Y, Homma T, Okumura H, Takahashi HE: Ganglion cyst occurring in the ligamentum flavum of the cervical spine. A case report. Spine (Phila Pa 1976) 17:1531-1533, 1992

57. ten Donkelaar HJ, Willemsen MA, van der Heijden I, Beems T, Wesseling P: A spinal intradural enterogenous cyst with well-differentiated muscularis propria. Acta Neuropathol 104:538-542, 2002
58. Vastagh I, Palásti A, Nagy H, Veres R, Bálint K, Karlinger $\mathrm{K}$, et al: Cervical juxtafacet cyst combined with spinal dysraphism. Clin Imaging 32:387-389, 2008

59. Xu R, McGirt MJ, Parker SL, Bydon M, Olivi A, Wolinsky JP, et al: Factors associated with recurrent back pain and cyst recurrence after surgical resection of one hundred ninety-five spinal synovial cysts: analysis of one hundred sixty-seven consecutive cases. Spine (Phila Pa 1976) 35:1044-1053, 2010

60. Yamamoto A, Nishiura I, Handa H, Kondo A: Ganglion cyst in the ligamentum flavum of the cervical spine causing myelopathy: report of two cases. Surg Neurol 56:390-395, 2001

Manuscript submitted March 4, 2013.

Accepted March 27, 2013.

Please include this information when citing this paper: DOI: 10.3171/2013.3.FOCUS1385.

Address correspondence to: Meic H. Schmidt, M.D., M.B.A., Department of Neurosurgery, University of Utah, 175 N. Medical Dr. East, Salt Lake City, UT 84132. email: neuropub@hsc.utah.edu. 